КОМПЕТЕНЦИИ ЗА СЬЗДАВАНЕ НА УЧЕБНИ РЕСУРСИ В ДИГИТАЛНА СРЕДА

Мима Дочева Трифонова

\title{
COMPETENCES FOR CREATING EDUCATIONAL RESOURCES IN A DIGITAL ENVIRONMENT Mima Docheva Trifonova
}

\begin{abstract}
The article presents the teacher's activity in terms of the educational resources they use in their teaching. Emphasis is placed on the opportunity for teachers to create their own educational materials in a digital environment. A classification of the educational resources has been made according to the purpose they serve and the digital objects they consist of. The pedagogical projections of digital objects in their role as components that make up the learning resources have been analyzed. The need to form hybrid competencies, in this case digital-pedagogical ones, for the students who would be future teachers in primary education has been explained.
\end{abstract}

Key words: educational resources, digital-pedagogical competences, student education, information technologies

\section{Въведение}

Свидетели сме на очертали се завишени очаквания към българския учител, изразяващи се в възможността да се справя не само с традиционно възприетите роли, но и с ролята му на новатор и адекватно реагиращ на предизвикателствата, произтичащи от специфичните потребности на новите поколения ученици. Тази ситуация предполага наред с притежаваните знания, умения и компетенции в професионално-педагогическата област, учителят да има и компетенции от областта на информационните и комуникационните технологии, отговорни за осъвременяване на неговата преподавателска дейност. В изминалите 20 години според утвърдена наредба за придобиване на професионална квалификация „учител” от 1997 година, формирането на дигитални компетенции за студентите от педагогически специалности се осъществяваше в рамките на регламентирана учебната дисциплина Аудио-визуални и информационни технологии в обучението (АВИТО), сьгласно приета учебна програма за всяко висше училище. Наред с това по повод на различни стратегии на МОН за интегриране на информационните и комуникационните технологии (ИКТ) в училище, се провеждаха 
краткосрочни обучения на действащи учители, целящи постигане на информираност за новостите в областта на ИКТ и възможностите им за подпомагане на учебни дейности и процеси. Новоприетата стратегия от 2018 година е с основен акцент за преход „от ползватели към създадели“. Интерпретацията на стратегията е преминаване от пасивно потребление на дигитални ресурси към създаване на собствени продукти и ресурси. Оказа се, че вече не е достатъчно да можеш да търсиш, намираш и директно да използваш създадено съдържание, предоставено от някой друг и хаотично разпространяващо се в мрежовото дигитално пространство. Необходими са знания, умения и компетенции за създаване на собствено дигитално съдържание с помощта на разнообразни инструменти и технологии. Акцентът е отместен от консуматорската към съзидателно-креативната проекция на дигиталните компетенции. И навременна е тази стратегия, защото студенти от новото Z поколение, обучаващи се в педагогически специалности, притежават потенциал да усвоят и развият успешно хибридни дигиталнопедагогически компетенции на базата на своята подготовка по учебната дисциплина Информационни технологии, изучавана в прогимназиалния и гимназиалния етап на училищното образование. Te са обучаемите, които преживяват в условия на постоянно присъствие на дигитални технологии в ежедневието и употреба на информационни ресурси от мрежовото дигитално пространство. Съгласно Наредба за държавните изисквания за придобиване на професионална квалификация „учител“ в сила от учебната 2017/ 2018 година наименованието на задължителната учебна дисциплина за педагогическите специалности е Информационни $u$ комуникационни технологии и работа в дигитална среда.

Един вариант за осъществяване на съзидателно-креативната идея е в обучението по избираемата учебна дисциплина Информационни технологии в първи курс, пьрви семестьр на студентите от специалност Предучилищзна и начална училищзна педагогика (ПНУП) и Начална училищна педагогика с чужд език (НУПЧЕ) да се реализира пьрвият етап от процеса на преминаване от консуматори към създатели, реализиран чрез обучение за създаване на учебни ресурси в дигитална среда. За целта е избран познат раздел от областта на информационните технологии, изучаван от всички студенти по време на обучението им в училище - раздел Текстообработка. Подбрани са значими теми от него, които са определящи за усвояването на специфични за приложението компетенции за използване на статични дигитални обекти като 
самостоятелни компоненти в учебните ресурси, както и теми, чието съдържание е свързано с използването на комбинации и връзки между дигиталните обекти, реализиращи дидактически варианти на представяне на учебно съдържание. За целта са привлечени разнообразни компоненти от тематични съдържания, предвидени за изучаване в за 1.-4. клас, представляващи най-често срещаните комбинации между текстове, изображения, таблици и графични форми. Основни компоненти на учебната среда за осъществяване на обучението на студентите са типологизираните задачи, чието изпълнение води до създаване на учебни ресурси или фрагменти от тях, използвани за подпомагане дейността на учителя. В дигиталната среда на приложението за текстообработка съществуват условия за усвояване и развитие на компетенции, успешно приложими и в други приложения и ситуации.

\section{Дигитална среда}

В технически смисъл дигиталната среда е виртуално, симулирано пространство, което е създадено посредством използването на един или повече компютъра и/или мобилни устройства. Потребителите извършват дейности в нея чрез използването на създадените технологии, осъществяващи автоматизиране на основните информационни дейности събиране, съхранение, обработка и разпространение на информация. Във връзка с използването на дигиталната среда в образователен контекст Георгиева-Лазарова (Georgieva-Lazarova, St., 2012, с.37-54) прави обобщение, от което могат да се изведат някои характеристики на дигиталната среда. Това е „новата образователна среда“ в която протича процеса на ,целенасоченото предаване и усвояване на педагогически адаптирания социален опит, на формиране, развиване и реализация на личността“. Тази среда е „ориентирана към организация на учебния процес в условия на наситено с дигитални технологии, пространство“. Тя се използва за „съхраняване и предоставяне на допълнителни учебни ресурси, изпълняващи помощна функция при традиционна форма на обучение“.

Многообразието от известни практики, свързани с използването на ИКТ в образователен контекст, налага да се направят уточнения в какъв контекст ще се използва дигиталната среда. В обучението на студентите бъдещи учители дигиталната среда ще се разглежда като място, в което присъстват технологии и инструменти, които се използват за създаване на дигитални информационни продукти, които в своята същност представляват учебни ресурси, предназначени за учениците и подпомагащи осъществяването на професионално- 
педагогическата дейност на учителя. Създаваните учебни ресурси в дигитална среда са предназначени за използване от учениците след разпечатване върху хартия. Съхраняват се от учителя в дигитален формат с възможност за многократно използване и пренасяне в други ситуации след извършване на модификации, от които се получават различни варианти на първоначално създадените учебни ресурси.

\section{Дейността на учителя}

Дейността на учителя ще бъде анализирана от гледна точка на нейната същност, видове и елементи като ще се акцентира на местата, където учебните ресурси, създавани от учителя, са определящи за нейното успешно осъществяване.

В своята същност дейността на учителя „...е предназначена да осъществява управление на активната и съзнателната дейност на учениците при усвояване на учебния материал“"(Тенева, 2012, с. 108). В определението е очертана ролята на учителя и взаимодействието му с предвиденото за усвояване учебно съдържание. Следователно предварителната подготовка на учителя за извършване на тази дейност включва подходяща интерпретация на учебния материал, която ще подпомогне реализацията на управлението на дейността на учениците в процеса на обучение. В подходящата интерпретация на учебното съдържание се включват различни варианти и форми за представянето му така, че да бъде достъпно за всички ученици. Дигиталната среда е удобно място за създаване и съхранение на различни форми на представяне на учебна информация и тяхната бърза трансформация от една в друга или за извършване на необходима модификация върху тях, за да са успешно употребими в друга ситуация.

В класификацията на И. Лернер за видове дейност на учителя се открояват две дейности, в които учебните ресурси, подготвени от учителя, имат отношение към осъществяване на дейността му. Пьрвата е дейност за преподаване на учебното сьдържание или за организация на неговото усвояване, а втората е дейност за осигуряване на обратна връзка от учениците към учителя, т.е. дейност за контрол на хода и резултатите от ученето (Lerner, 1980). Първата дейност може да се подпомогне успешно чрез създадени учебни ресурси за онагледяване, а втората чрез учебни ресурси, които са създадени като задачи за изпълнение от учениците. Подготовката на учебни ресурси и за двете дейности е възможна в дигитална среда с използването на подходящи инструменти за създаване и обработка на учебни компоненти, участващи в цялостен ресурс.

Бабански (Babanski, 1988, с. 136-140) откроява в дейността на 
учителя няколко елемента. Интерес за темата представлява елементът, „организация на учебната работа на учителя“ със своите два етапа - подготвителен и изпълнителен, където е посочено, че е необходимо учителят да осигури необходимите технически средства, нагледни помагала, дидактически и раздавателен материал. Същността и пълнотата на този елемент може да бъде съвременно обезпечена от възможностите на дигиталните технологии чрез създаване на дидактически ресурси, състоящи се от дигитални обекти и съответно разпечатване на ресурса върху хартия за директно използване от учениците. Елементьт, организация на дейността на ученищите 6 , в който се включват компоненти като поставяне на учебни задачи и създаване на благоприятни условия за възприемане на задачите, също е възможно да бъде реализиран в условията на дигитална среда. Дигиталната среда на приложението за текстообработка дава възможност за изграждане, съхранение и разпечатване на работни листи с условия на задачи, в които е необходимо попьлване на липсващи елементи или връзки, ограждане на обекти, допълване на учебно съдържание или изискуеми елементи и др.

Според Тенева, учителят е „основен източник на дидактически редуцирана информация“, което е предпоставка учениците „да се ориентират бързо в нарастващия поток от информация“, а учебникът е нужен на учителя „за да се ориентира в определените граници, в които трябва да се движи съобразно възрастовите особености и целите на обучението“( Teneva, 2012, с. 164-165). T.е. в дейността на учителя е очертана ролята му и са регламентирани рамките на полето от учебна информация за съответната възраст, а учителят има възможност да търси и намира оптимален начин за подходяща интерпретация на учебното съдържание като създава свои авторски учебни ресурси за постигане на заложени цели в обучението. Адаптираните текстове, табличните форми на представяне на информация, изображенията с изнесени означения, схемите на последователности и етапи на процеси и задачите за изпълнение от учениците са част от възможните реализации на учебни ресурси, осъществими в дигиталната среда на приложението за текстообработка.

В своя анализ на ефективността на училищното учене Тенева (Teneva, 2016, с.60) определя 7 условия, свързани със стимулирането на ученика от учителя във връзка с повишаването на качеството на процеса на обучение и съответно повишаване ефективността както на преподаването, така и на ученето. В три от тях се открива прякото 
участие на учебните ресурси като отговорни за изпълнението на условията:

„поддържане на любопитството“ - може да се осигури чрез учебните ресурси, представящи учебната информация в различни формати, които задържат вниманието и възбуждат любопитството на учениците;

„осигуряване на разнообразни дейности“" - може да се осъществи чрез предварително подготвени учебни ресурси като таблици, изображения и схеми, в които е систематизирано учебно съдържание или е необходимо да се извлече информация по темата, за да се попълни или допълни на определени места в задачи от работни листи;

„осигуряване на практическа приложимост на знанието“изисква съставяне на задачи за изпълнение от различен практически характер, стимулиращи самостоятелната дейност на ученика и провокиращи творческите му изяви.

Учебният процес е невъзможен без активната дейност на учениците. Необходимо е учителят да осигури проявата на активност у учениците чрез създаването и използването на учебни ресурси, които поддържат любопитството на ученика, осигуряват му разнообразни дейности и практическа приложимост на наученото. Осъществяването на качествения скок от осмисляне към просветление може да се подпомогне от учебните ресурси, предназначени за самостоятелно извършване на повторения в разнообразни ситуации, защото за всеки ученик е необходимо различно време за настъпване на просветлението.

Интересен проблем поставя В. Делибалтова: „Проблемът, който винаги се очертава на равнището на конструирането на обучението или поне на институционализираното обучение, е как да се адаптира определено съдържание по посока на определени цели към индивидуалните особености на учениците“" (Delibaltova, 2004, с.83). За да бъде улеснен учителят при адаптирането на определено учебно съдържание е необходимо той да притежава компетенции за използване на подходяща среда с инструменти, където да осъществява дейности по създаване на учебни ресурси с различен формат, насочени към реализация на определени цели.

Избраните и анализирани компоненти от дейността на учителя се отнасят към предварителна му подготовка за осъществяването на преподаването и ученето. Дейностите, по подготовката е възможно да се реализират в дигитална среда и са свързани с преработване, преобразуване и преструктуриране на учебна информация така, че 
да се осигури достъпност на голяма част от учебното съдържание за по-голям брой обучаеми. Това предполага една продължителна предварителна работа на подготовката за преподаването и реализацията на ефективно учене. Необходимо е учителят да:

подготвя подходящи адаптирани форми на фрагменти от информация в тематична единица, интерпретиращи учебното съдържание в нея чрез: създаване, структуриране и форматиране на текстова информация; звеждане на информация от учебно съдържание в табличен вид; създаване, редактиране и форматиране на графична информация, онагледяваща учебно съдържание; комбиниране на текстова и графична информация в схеми за онагледяване.

подготвя учебни ресурси от тип задачи, предвидени за изпълнение от учениците, изискващи извършване на дейностите: допълване, свързване, изброяване, подчертаване, ограждане, попълване на таблици, дописване и извършване на повторения и др.

сьхранява в дигитален формат колекции от учебни ресурси, за да бъдат в удобен формат за модифициране и използване във вариативна ситуация или да бъде лесно и удобно трансформирането им при използване в друго приложение.

\section{Характеристики на учебните ресурси}

За установяване на съответствията между учебни ресурси, представящи учебно съдържание и потребните компетенции на студентите за създаване на учебни ресурси в дигитална среда, ще бъде направена характеристика на учебните обектите от гледна точка на педагогическите им проекции и от гледна точка на дигиталната им същност.

Характеристика на обектите в учебните ресурси от гледна точка на педагогическите им проекции.

Учебните обекти са част от учебното съдържание. Учебният обект е функционално обособен и може да бъде трансформиран, модифициран, комбиниран с други. Общите признаци за различните образователни направления, в които се създават учебни ресурси са: отразяване на основни компоненти от учебното съдържание с разнообразни нагледни средства; отразяване на основни дейности, които се предвижда да извършват учениците при изпълнение на самостоятелни задачи.

Текстьт е основно средство за представяне на учебна информация . За осигуряване на възприемането му е необходимо да бъде подходящо подреден, форматиран с избран шрифт, абзац, цвят, начертание, местоположение. Текстьт в учебните ресурси се използва 
в дълги пояснителни изречения, в обособени части за изводи и обобщения, в условията на задачите или указания за тяхното изпълнение, в дидактически тестове с избираем отговор, в надписи към изображения, в изнесени пояснителни текстове към илюстрации, в клетки от таблица, в надписи на графични форми и съдържание в текстови полета. Многоточие или последователност от долни чертички могат да указват необходимостта от попълване на липсващи букви или думи. При вмъкване на символи, които ги няма на клавиатурата, се обогатяват възможностите за създаване на математически задачи.

Илюстрациите са нагледно средство в обучението. Те обогатяват визуалната представа и подобряват естетическия вид на съдържанието, използват се в местата, където учебното съдържание е трудно за разбиране. Те улесняват възприемането на текста и представят в синтезиран вид част от информацията, съдържаща се в него. При тяхното използване не бива да се прекалява с количеството им. Необходимо е на места да липсват илюстрации, за да възникнат въпроси, които да предизвикат проявата на активност от страна на ученика. Една обща класификация на нагледните средства разпределя илюстрациите в три вида: изобразителна нагледност, условнографична нагледност, мултимедийна нагледност. За целите на обучението на студентите, бъдещи учители за създаване на учебни ресурси в дигитална среда е изключен типьт мултимедийна нагледност, а са разгледани само статичните форми на изобразителна и условно-графична нагледност.

Към изобразителната нагледност спадат картини, фотоизображения от обкръжаващия свят, рисунки и др. Подборьт им се прави от съдържанието на собствени колекции от фотоизображения, сканирани изображения от хартиен носител, рисунки, създадени в графични редактори и подбрани изображения от дигиталното мрежово пространство. Тяхното присъствие в учебните ресурси е необходимо да бъде съпьтствано от пояснителни текстове, а варианти за подредбата на картини може да реализират при вмъкването им като съдържание в клетки от таблица.

Към условно-графичната нагледност се причисляват таблиците, схемите, блок-схемите, чертежите и др.

Таблицата е универсален начин, който предлага възможност за структуриране на данни и подредба на информация по някакъв принцип, където всяка клетка е предназначена за отделен обект. Като дидактически ресурс за онагледяване, тя е изградена на базата на: извлечени съществени характеристики на обекти и явления, 
описани в учебната информация; извършени класификации на подбрано съдържание; разпределение на информация в подходяща последователност. Таблиците служат за повишаване на зрителната нагледност, групиране на еднотипни обекти, систематизиране на информация, сравняване на два или повече обекта и др. Подпомагат осмислянето на взаимовръзки и отношения между изучавани понятия, факти, явления, позволяват бързо откриване на нужната информация. Таблиците се използват успешно и при учебните ресурси, съставени като задачи за изпълнение от учениците. Някои от дейностите, предвидени за извършване върху разпечатания им хартиен вариант са: попълване на липсващ текст в клетка/и; свързване на думи или обекти, разположени в колонки от таблица; подреждане и класификация на предоставени обекти.

При схемата реалните обекти от действителността и връзките между тях са заменени с условни и символни означения, представени чрез графични форми и надписи в тях или до тях. Схемите заемат малка площ. Учебната информация в тях е опростено представена, отразено е основното съдържание. Схемите илюстрират динамиката на изучаваните процеси като показват: смислови и асоциативни връзки; преходи от хронологично и логическо естество; съществуващи причинно-следствени връзки между понятия от изучавано тематично съдържание и др. Използването на схеми като учебни ресурси помага при възприемане и запомняне на правила, последователности, закономерности, циклични процеси и др.

Блок-схемите са един от начините за изразяване на алгоритми. В тях се използват различни по форма блокове. Отделните блокове характеризират еднотипни по същността си елементарни действия. Най-често използваните блокове са: за начало; за елементарно действие; за логическо условие; за вход; за край и др. В тях се съдържат данни, с които трябва да се изпьлни алгоритьм. До сега присъствието на блок-схеми като учебни ресурси за онагледяване в учебно съдържание за началния етап на основната образователна степен е частично застьпено, но вече предстои неговото задължително присъствие във връзка с новия учебен предмет Компютьрно моделиране, чието изучаването стартира от учебната 2018/2019 година за учениците в трети клас и продължава и през следващата учебна година в четвърти клас. В учебните ресурси, създадени като задачи за изпълнение, блок-схемите могат да бъдат представени като структури, а от учениците да се изисква да ги попълнят със съдържание, отговарящо на даден алгоритъм или да разпознаят коя блок-схема на кой алгоритъм съответства. 
Чертежите в учебното съдържание за начален етап на основната образователна степен присъстват предимно в учебното съдържане по математика, където са компоненти на задачи, в които са представени основни геометрични фигури или конкретни обекти, съставени от различни геометрични форми. Означенията за размери на частите на обектите са поставени в отделни текстови полета. Техните стойности се използват при пресмятане на математически изрази в задачи. В други учебни ресурси чертежите могат да се използват като основа за извършване на измервания и записване на конкретни стойности като дължини на отсечки, страни от геометрични фигури и др.

В учебните ресурси, създадени в дигитална среда, учебното съдържание се създава и трансформира до компоненти като: дълги и кратки текстове, автоматични списъци, таблици с текстово и графично съдържание, схеми, изображения, чертежи и др., които успешно могат се използват във вариант за онагледяване на учебно съдържание и във вариант на задачи за изпълнение от учениците. Учебните ресурси улесняват управлението на познавателната активност на обучаемите. Веднъж създадени в дигитална среда, могат да се използват многократно. Те подпомагат дейностите по проверка и контрол на усвоеното от учениците учебно съдържание.

Характеристика на обектите в учебните ресурси от гледна точка на дигиталната им същност

Характеристиките на обектите ще бъдат изведени при условия на използването им като самостоятелни обекти и условия на използването им в комбинация с други дигитални обекти. Учебните ресурси, предназначени за разпечатване, са съставени основно от дигиталните обекти текст, изображение, таблица, графична форма. Превръщането на дигиталните обекти в компоненти на учебно съдържание се осъществява чрез: промяна на техните параметри по отношение на външен вид (размер, цвят, местоположение); промяна на взаимното им положение; създаване на връзки между тях, отразяващи смислови отношения. Образуването на различни комбинации от дигитални обекти ги преврьща в композиции, които имат необходимата функционалност и обслужват заложена дидактическа цел.

\section{Дигитална същност на текста}

Обектът текст се създава по различни начини: набиране на текст от клавиатурата, копиране на готов текст от външен файл; оптично разпознаване на сканирано текстово съдържание. Операциите, които се извършват върху създадения текст са 
редактиране на символи или думи (изтриване, заместване, вмъкване) и редактиране на абзаци (добавяне и изтриване на абзаци, образуване на нови изречения, промяна границите на дълги изречения, сливане на два съседни абзаца в един, разделяне на абзац на два или повече абзаца). Параметрите на текста, които могат да се променят са параметри за шрифт (вид, размер, ефекти и др.) и параметри за абзац (подравняване, отстъпи, разредки, оцветяване, граници, автоматични списъци - изброяващ и номериран и др.). Операциите редактиране и форматиране на символи и абзаци оформят учебния текст в подходяща за възприемане визуална форма.

\section{Дигитална сыщност на таблицата}

Таблицата като самостоятелен обект

Обектът таблица се създава с помощта на вградените възможности на приложението за текстообработка по предложен макет, показващ структурата на таблицата като размер (брой колони и брой редове) или чрез инструмент за начертаване. Таблица в текстов документ може да се копира от друг файл или от друго приложение (например Microsoft Excel). Операциите, които могат да ce извършват върху създадената таблица, за да се промени нейната структура са: добавяне и премахване на редове и колони; обединяване и разделяне на клетки. Параметрите на таблицата, които могат да се променят са: ширина на таблицата; размер на клетките (височина на ред, ширина на колона); стил на таблицата; оцветяване фон на клетки; премахване и поставяне на различни граници на клетки.

\section{Комбинация на таблица с текст}

При комбинация на таблица с текст параметрите, които могат да се променят касаят начина, по който ще се разполага текстовото съдържание в отделните клетки на таблицата. Всяка клетка от таблицата прилича на една малка страничка в документ и въведеното в нея може да се форматира с познатите параметрите за шрифт и абзац. Като допълнителна възможност за форматиране на съдържанието в клетка се предлага подравняване на текста по вертикала и промяна посоката на текста.

\section{Дигитална сыщност на изображението}

Изображението като самостоятелен обект

Обектът изображение (картина или Picture) в текстовия документ се вмъква от предварително съхранени графични файлове в папка или от графичната колекция на приложението за текстообработка. Изображенията могат да се копират от произволно място в мрежата без да е необходимо да се запазват предварително като файлове на определено място. След изпълнение на командите 
за вмъкване или копиране, изображението се позиционира по подразбиране пред мигащия маркер на текущия абзац и остава там като символ от текста, т.е. текстьт и изображението се намират в общ слой. При кликване върху изображението то се маркира и около него се появяват т.нар. водачи. В менюто на приложението за текстообработка е налична лента с инструменти за неговата обработка. Операциите, които могат да се извършват върху изображението са: изрязване и премахване на излишни части от него, завъртане и обръщане, компресиране и др. Параметрите на изображението, които могат да се променят са: размер (височина и ширина); подравняне в рамките на абзаца, в който се намира изображението. Допълнителни възможности за оформлението му са: задаване на граница (контур) и визуални ефекти; избор на готов стил; художествени ефекти и цветови корекции; премахване на фон и др.

\section{Комбинация на изображение с текст}

При първата комбинация двата обекта - изображението и текста се намират в общ слой. Височината на изображението предизвиква появата на празни полета, в които не може да се помести текст. Този вариант на взаимно положение е подходящ в случаите когато изображението се разполага самостоятелно в рамките на един абзац или с други изображения до него. Други варианти на взаимно положение поставят обекта изображение в отделна равнина, т.е. върху текста или като фон под текста, както и опция, при която текстът обтича изображението по неговите контури. Всеки от тях има своите предимства и недостатъци. Един вариант на успешна комбинация между изображение и текст е абзацът с текст да бъде форматиран с необходимите отстьпи отляво или отдясно и в освободените бели пространства да се помести изображението с опция, форматираща го в отделна равнина от текста.

\section{Комбинация на изображение с таблица}

В таблиците могат да се разполагат и подравняват изображения. Принципът на оформление е същия като при комбинация на текст и таблица. Изображението се разполага в клетка от таблица, размерите на клетките се променят, за да осигурят място за изображението и понякога това създава неудобства при обработка. Добър вариант на работа е изображението да бъде вмъкнато на самостоятелен абзац извън клетките на таблицата и след форматиране с подходящи размери да бъде преместено в съответната клетка. Изображението трябва да остане с опцията, която има по подразбиране за позициониране „В текста“, за да са достъпни възможностите за неговото хоризонтално и вертикално подравняване спрямо границите 
на клетката, в която се намира.

\section{Дигитална същност на графичната форма}

Графичната форма като самостоятелен обект

Обектът графична форма се вмъква в текстовия документ от вградена библиотека, съдържаща раздели с различни линии, геометрични фигури, блокови стрелки, изнесени означения и др. Характерно за тези графични форми е, че те са изображения от тип векторна графика и при увеличаване на размерите им не се губи тяхното качеството. Аналогично на изображенията, вмъкнати от файл, и графичните форми се заграждат с рамка от водачи като се появява допълнителна лента в приложението, която предоставя инструменти за тяхната обработка. При вмъкването им в текстовия документ графичните форми имат опция спрямо текста, определяща разположението им в отделна равнина, зададена по подразбиране да бъде върху текста. Това ги отличава като поведение от изображенията, вмъкнати или копирани от външен графичен файл. Операциите, които могат да се извършват с графичните форми са: свободно преместване върху текста или празните пространства в документа, копиране и добавяне на текст вътре в тях. Някои от фигурите могат да бъдат трансформирани до друг техен вариант или редактирани в определени участъци. Параметрите на графичната форма, които могат да се променят са: размер, стил, цвят на запълване, цвят на контур, ефекти, завъртане, обрьщане. Всяка готова форма, вмъкната в текстовия документ, може да бъде форматирана по отношение на местоположение спрямо текста, подреждане, спрямо други графични обекти и групирана с други графични обекти и графични форми. Графичните форми най-често се използват за да се изгради с тях схема, блок-схема или чертеж, т.е. в учебния ресурс участват много на брой форми, върху които са приложими дейностите подреждане, групиране и подравняване.

\section{Комбинация на графична форма с текст}

По аналогия на комбинацията между текст и изображение, се реализира и комбинацията между текст и графична форма. Повечето графични форми допускат добавянето на текст вътре в тях. След неговото въвеждане той принадлежи на формата и се премества и завърта заедно с нея. За формите, в които няма възможност да се добавя текст е подходящо в близост до формата или върху нея да се добави обект текстово поле с премахнати граници и за удобство двата обекта да се групират в един общ обект.

Комбинация на графична форма с таблица

Тази комбинация се реализира по аналогия на комбинация на 
изображение с таблица. За удобство при работа е подходящо графичната форма се изчертава извън таблицата. Променя се опцията за взаимно положение на текста и формата с опция „В текста“. След задаването на тази опция формата се позиционира в началото на найблизкия абзац. При това състояние вече е удобно да бъде поместена в избрана клетка от таблицата и подравнена в рамките на клетката.

\section{Комбинация на графична форма с изображение}

Графичните форми и изображенията имат аналогични характеристики и поведение в текстовия документ. При създаване на комбинации между тях се използват възможностите за подреждане (Премести напред, Изпрати назад), групиране, подравняване. При изпълнението на дейностите групиране и подравняване се налага обектите да бъдат разположени в различна равнина от текста и да бъдат едновременно избрани.

Комбинация между дигиталните обекти текст, таблица, изображение и графична форма

Създаването на учебни ресурси, в които присъстват едновременно текстови и нетекстови обекти, изисква те да бъдат коректно комбинирани помежду си и подредени така че да е възможно тяхното безпроблемно групиране, копиране и пренасяне от един файл в друг или от едно компютьрно приложение в друго. Един вариант за рационално комбиниране, който запазва достьпа до всеки обект, е вмъкването на всички дигитални обекти в графичната форма Платно за рисуване, където всеки от тях се разполага в отделна равнина, определена от реда на вмъкването им.

Платното за рисуване представлява самостоятелен обект, който при вмъкване в текстов файл се разполага на самостоятелен абзац и като графичен обект има опция за оформление „В текста“. Това позволява да се изолират един от друг участьците, в които преобладава текст, оформен в абзаци, от участъците, в които има комбинация между текстови и нетекстови елементи, оформени в композиция. Параметрите на платното, които могат да се променят са размери, контур, запълване, ефекти, които се използват по аналогия на работата с другите графични форми от същата група. Платното обединява обектите, които са вмъкнати в него и представлява една удобна възможност за извършване на дейностите групиране, подреждане и подравняване за всеки дигитален обект. Произволното разположение на текстова информация в рамките на платното се реализира чрез поместване на текст в обекта текстово поле. Текстовото поле е удобно и при поместване на дигиталния обект таблица в Платно за рисуване. Тази форма на организация създава 
удобства за бързо извършване на малки промени по създадената композиция, за да се получат нейни модифицирани варианти, подходящи за употреба в други ситуации.

Всички описани обекти (текст, изображение, таблица, графична форма) са елементи на дигиталната среда на приложението за текстообработка. Всеки от тях има своята специфична сыщност, определяща го като начин, по който се създава и визуализира в рамките на текстовия документ. Върху всеки обект могат да се извършват множество операции за редактиране и задаване на опции, определящи взаимното му положение спрямо другите обекти. Всеки дигитален обект може да бъде форматиран чрез промяна на неговите параметри за цвят, размер, местоположение и др. За вмъкването, създаването, обработката, съхранението им, както и реализирането на комбинации между тях са налични подходящи инструменти с различни възможности. С тях дигиталните обекти се оформят като самостоятелни компоненти или като комбинации, които изграждат учебните ресурси за онагледяване на учебно съдържание и/или задачи за изпълнение от учениците. Учебните ресурси онагледяват процеси, явления, последователности, причинно-следствени връзки, класификации, изнесени означения, части от цяло, цикличности и др. Примери за учебни ресурси, които са задачи за изпълнение от учениците са: групиране на обекти по различни признаци чрез ограждане; изчертаване на свързващи линии между съответстващи обекти; ограждане на излишна фигура или текст; свързване на съответствия - дума с изображение; поставяне на знаци за сравнение; попълване на липсващи числа в редица; откриване на геометричните форми в композиция; откриване на грешки, пропуски и съответствия; задачи с избираем отговор и др.

Учебните ресурси илюстрират идеи за представяне на учебно съдържание, изградено като комбинация от статични компоненти от текстов и графичен тип, която:

· функционира като средство за осъществяване на дидактическа идея на учителя;

- предназначена е за разпечатване върху хартия;

- насочена е към подпомагане реализирането на учебния процес с учениците в определена тематична единица от учебните дисциплини за начален етап на основната образователна степен.

Направената характеристика на учебните обекти от гледна точка на педагогическите им проекции и от гледна точка на дигиталната им същност отразява хибридния характер на компетенциите, необходими за успешното създаване на учебни ресурси в дигитална 
среда от студентите бъдещи учители в начален етап на основната образователна степен. В статията „Дигитално-педагогически компетенции (от потребителска към съзидателно-креативна стратегия)“" е направено обобщението, че понятието „дигиталнопедагогически компетенции обозначава в достатъчна степен тяхната специфика за студентите, бъдещи учители при реализация на дейности в дигитална среда, водещи до създаване на учебни ресурси и продукти, предназначени за осъвременяване на професионалнопедагогическата им дейност.“"(Trifonova, 2018, с.14).

Върху едно и също учебно съдържание могат да се създават ресурси и от двата вида - за онагледяване и задачи за изпълнение от учениците. При коректно и целесъобразно оформление на дигиталните обекти в учебните ресурси за онагледяване, те могат успешно да се трансформират по рационален и бърз начин в ресурси, които да бъдат задачи за изпълнение от учениците. Рационалната трансформация и модификация на учебните ресурси от един вид в друг и осигурената възможност за техния пренос в друго приложение или ситуация са част от присъщите компоненти на дигиталнопедагогическите компетенции, които се усвояват в процеса на обучение по учебната дисциплина Информационни технологии за студентите бъдещи учители в начален етап на основната образователна степен.

Дигитално-педагогическите компетенции могат да се обособят като два типа компетенции: за създаване на учебни ресурси и за модифициране на учебни ресурси. В зависимост от съставните части на учебните ресурси, те могат да бъдат определени като съставени от еднотипни дигитални обекти (само текстове, само таблици като структури, само изображения, само графични форми) или съставени като комбинация между текстови и нетекстови обекти (различни комбинации между текст, таблица, изображение, графична форма). Варианти за модифициране на учебни ресурси са: преврьщане на текстов образователен ресурс в задача за допълване на липсващи думи, понятия; от таблица за визуализация на учебно съдържание в задача за учениците за попълване на липсващи елементи в нея; от схема за визуализация на процес или явление в задача за учениците за добавяне на липсващи елементи, връзки, текст. Компетенциите за създаване и компетенциите за модифициране на учебни ресурси са взаимосвързани, защото отразяват същността учебното съдържание от две различни гледни точки - като онагледяване и като задачи за изпълнение от учениците. 


\section{Обучение на студенти от педагогически специалности}

От направена диагностика на подготовката на студентите по учебната дисциплина Информационни технологии от гимназиалния етап на средното училище е констатирано, че възприемат фрагментарно дигиталните обекти и извършват формално възможните комбинации между тях без да проявяват нужната прецизност при подбор на подходящи параметри оформлението им. За да притежава нужната функционалност, в ролята ] на учебен ресурс, създадената комбинация от дигитални обекти е необходимо да има конкретно подбрано съдържание и реализирани връзки между отделните нейни части. За обучението на студентите бъдещи учители по учебната дисциплина Информационни технологии в първи курс, първи семестьр е моделирана преднамерена среда, която включва изпълнението на типологизирани задачи за създаване на статични дигитални учебни ресурси в интегрираното пространство на приложението за текстообработка. Студентите създават дигитални ресурси по подобие на готови ресурси, които са публикувани и използвани в учебниците и учебните помагала за начален етап на основната образователна степен (1.-4. клас) по отделните учебни дисциплини. При осъществяване на предвидените дейности по реализация на задачите се открояват в неявен вид и основни дигитални компетенции като: търсене, намиране, съхранение, обработка на информация и др., които се извършват предварително в дигитална среда, а готовите обекти се внасят за допълнителна обработка в средата на приложението за текстообработка.

Усвоените дигитално-педагогически компетенции в резултат на провежданото обучение със задачно-базирана технология осигуряват възможност на студентите в следващия етап от обучението си в бакалавърската степен да изграждат учебни ресурси в дигитална среда, базирайки се на дидактически принципи и свои самостоятелни идеи, съобразени с целите, заложени в учебните програми по съответните учебни дисциплини за началния етап на основната образователна степен. Усвоените дигитално-педагогически компетенции са успешно преносими и при обучението на студентите в учебната дисциплина Информационни и комуникационни технологии и работа в дигитална среда, изучавана през втори семестър на първи курс, където създаването на учебни ресурси продължава с реализацията на мултимедийната нагледност и създаването на динамични учебни ресурси в дигитална среда. 


\section{Заключение}

Дейността на учителят по отношение на учебните ресурси, които използва, е свързана с тяхното проектиране, създаване и съхранение чрез възможностите, предоставяни в дигиталната среда. Необходимо е да притежават: компетенции за избор на подходящи компоненти и технология за създаване на учебен ресурс; компетенции за модифициране свойствата и характеристиките на отделните компоненти на учебните ресурси, за получаване на оптимално взаимодействие между тях по отношение на тяхната цялост в дидактически вид и възможността за многократно използване.

Учебните ресурси, създадени от учителите, и предназначени за учениците, са една възможност за осмисляне на учебното съдържане в рамките на структурирания учебен процес и полето на общата им активност. Учебните ресурси разнообразят формите на представяне на учебния материал, подобрят процеса на възприемане на понятия и взаимовръзки, представят учебното съдържание под формата на задачи за изпълнение от учениците, подпомагат самостоятелната дейност на учениците в учебния процес, и разнообразяват вариантите на задачи за проверка и контрол на резултатите от обучението. Всичко това е предпоставка за проява на иновативно поведение на бъдещите учителите при решаване на проблеми чрез използване възможностите на дигиталната среда.

Усвояването и развитието на компетенции за самостоятелно създаване на учебни ресурси в дигитална среда - дигиталнопедагогически компетенции, е предпоставка за преодоляване на наблюдаваните негативни тенденции, произтичащи от мултиплицирането на готови учебни ресурси, свободно разпространявани в мрежовото дигитално пространство. Студентите бъдещи учители ще могат да създават собствени колекции от учебни ресурси и материали, в които ще могат да извършват периодични промени, свързани с добавяне, модифициране, трансформация и обогатяване, за да придобиват учебните ресурси подходящ формат за използване в различни ситуации.

Обучението по учебната дисциплина Информационни технологии с използване на типологизирани задачи детайлизира процеса на създаване на учебни ресурси в дигитална среда, акцентирайки върху съставни им части и връзки помежду им и технологията за тяхната обработка. Учебните ресурси, създавани от студентите в дигитална среда имат относително завършен вид. Те притежават необходимата функционалност и съдържание, но са отворени за модификации по отношение на добавяне на елементи, 
реализиране на нови връзки, трансформация на дигитални обекти до друг формат, заместване на съществуващи обекти с други подобни и изменения, създаващи вариативност в композицията от дигитални обекти.

\title{
Литература:
}

Babanski, Yu.K. (1988). Pedagogika. Sofia, Narodna prosveta. [Бабански, Ю.К. (1988). Педагогика. София, Народна просвета.]

Delibaltova V. (2004). Za obuchenieto. Mezhdu dadenoto i tarsenoto. Sofia: IK „Lik“. [Делибалтова В. (2004). За обучението. Между даденото и търсеното. София: ИК ,Лик“.]

Georgieva-Lazarova, St. (2012). Obuchenie v digitalna sreda. UI „Sv. sv. Kiril i Metodij“, Veliko T"rnovo. [Георгиева-Лазарова, Ст. (2012). Обучение в дигитална среда. УИ „Св. св. Кирил и Методий“, Велико Търново.]

Lerner, I.Ya. (1980). Proces obuchenia i ego zakonomernosti. Moskva, Znanie, seria „Pedagogika i psihologia“, kn.3. [Лернер, И.Я. (1980). Процес обучения и его закономерности. Москва, Знание, серия „Педагогика и психология“, кн.3.]

Teneva, M. (2012). Ovladyavane na didakticheska problematika ot studenti. Parva chast. Stara Zagora. [Тенева, М. (2012). Овладяване на дидактическа проблематика от студенти. Пьрва част. Стара Загора.]

Teneva, M. (2016). Efektivnost na uchilishtnoto uchene (3.-4. klas). Stara Zagora. [Тенева, М. (2016). Ефективност на училищното учене (3.-4. клас). Стара Загора.]

Trifonova, M. (2018). Digitalno-pedagogicheski kompetencii (ot potrebitelska kam sazidatelno-kreativna strategia) V: Science and technologies: Volume VIII, http:// www.sustz.com/journal/7/1767.pdf [Трифонова, М. (2018). Дигитално-педагогически компетенции (от потребителска към съзидателно-креативна стратегия) B: Science and technologies: Volume VIII, http://www.sustz.com/journal/7/1767.pdf ]

Naredba za darzhavnite iziskvania za pridobivane na profesionalna kvalifikatsia „uchitel”. (Obn. - DV, br. 89 ot 11.11.2016 g., v sila ot uchebnata 2017/2018 godina) [Наредба за държавните изисквания за придобиване на професионална квалификация „учител”. (Обн. - ДВ, бр. 89 от 11.11.2016 г., в сила от учебната 2017/2018 година)]

Naredba za edinnite darzhavni iziskvania za pridobivane na profesionalna kvalifikatsia „uchitel”. DV br. 34 ot 29. 04. 1997., i posl. izm. i dop.. [Наредба за единните държавни изисквания за придобиване на професионална квалификация „учител”. ДВ бр. 34 от 29. 04. 1997., и посл. изм. и доп.]

Uchebni programi za III klas v sila ot uchebnata 2018-2019 godina. https:// www.mon.bg/bg/1689, [poseten na 11.10.2018] [Учебни програми за III клас в сила от учебната 2018-2019 година. https:/www.mon.bg/bg/1689, [посетен на 11.10.2018]

Educate to create: from digital consumers to digital creators. https:// educatetocreate2018.bg/, [посетен на 27.06.2018]

\author{
Author Info: \\ Asst. prof. engineer Mima Trifonova \\ Trakia University - Stara Zagora \\ Faculty of Education \\ E-mail: mm trifonova@abv.bg
}

